\title{
Performance analysis of a 2-stroke micro free-piston swing engine*
}

\author{
Zhang Shimin ${ }^{1 * *}$, Guo Zhiping ${ }^{2}$ and Wang Jinsong ${ }^{3}$ \\ ${ }^{1}$ School of Mechanical and Electronic Engineering, China University of Petroleum, Beijing 102249, China \\ ${ }^{2}$ College of Mechanical Engineering, Inner Mongolia University of Technology, Hohhot, Inner Mongolia 010051, China \\ ${ }^{3}$ Department of Precision Instrument and Mechanology, Tsinghua University, Beijing 100084, China
}

\begin{abstract}
The micro free-piston swing engine (MFPSE) is a new structure, free-piston internal combustion engine. The dynamic model integrated MFPSE with a power generator and thermodynamic models in compression, power and scavenge processes based on the open thermodynamic systems were presented. A simulation was executed at given geometric parameters and initial conditions. The results manifest that the working principle of MFPSE is feasible.
\end{abstract}

Key words: Micro free-piston swing engine, working principle, performance simulation

\section{Introduction}

With the fast development of the military and civil portable electronic devices, the need for high energy density man-portable power sources is more and more urgent. Due to the problems of low energy density, long charge time, and pollution, chemical batteries do not meet this kind of demand. The study of high energy density power sources has already received extensive attention by academia and business circles, and it is gradually becoming a new research field.

Micro/miniature man-portable power generation systems, driven by micro/miniature internal combustion engines have already become an important research direction (Epstein et al, 1997a; 1997b; Fernandez-Pello, 2002). Micro rotary internal combustion engines (Fu et al, 2001a; 2001b; 2001c), micro gas turbine engines (Waitz et al, 1998; Mehra, 2000; Isomura and Tanaka, 2002; Epstein, 2003; Isomura et al, 2004; Shan et al, 2004), and micro internal combustion swing engines (Kudijiang, 2000; Werner et al, 2002) are mainly investigated to power micro electric generators.

A novel micro free-piston swing engine (MFPSE) was put forward by Zhang et al (2005). The MFPSE works on a twostroke cycle and possesses a simple and compact structure. The mechanical friction loss of the piston against the body wall is relatively low.

The existing theory of conventional internal combustion engines can not be adopted to analyze MFPSE directly because the compression ratio of an MFPSE is not fixed. It is necessary to set up a new method to evaluate the MFPSE's performance, consequently providing information for the

\footnotetext{
* National Natural Science Foundation (50375078), Key Discipline Construction Program of Beijing.

** Corresponding author. email: smzhang@cup.edu.cn

Received September 6, 2008
}

design of MFPSE.

In this paper, MFPSE and generator is regarded as a whole system, the dynamic model and thermodynamic models of MFPSE are presented, and the convergence criterion is also discussed. The performance of the MFPSE is simulated, thus the feasibility of the MFPSE is verified on operation principles.

\section{Dynamic model of MFPSE}

Fig. 1 is the schematic diagram of the MFPSE.

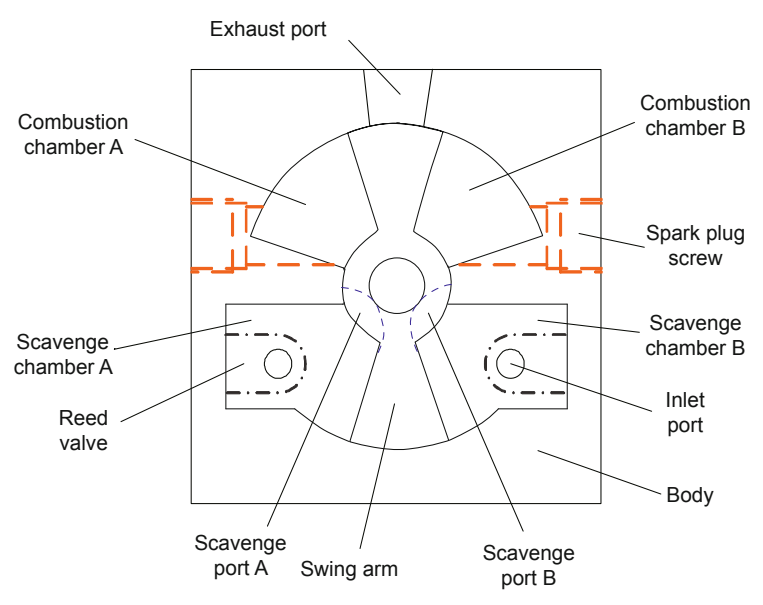

Fig. 1 Schematic diagram of MFPSE

For an MFPSE, assuming that the combustion chamber A is undertaking a power stroke; combustion chamber $\mathrm{B}$ is on the compression stroke; scavenge chamber A, compression stroke; and scavenge chamber $\mathrm{B}$, intake stroke. The moving direction of center swing and the forces exerted on it are shown in Fig. 2. According to Newton's second law, the swing angular acceleration can be expressed as: 


$$
I \ddot{\theta}=\left(p_{\mathrm{A}}-p_{\mathrm{B}}\right) A_{\mathrm{R}} L_{\mathrm{R}}-\left(p_{\mathrm{C}}-p_{\mathrm{D}}\right) A_{\mathrm{S}} L_{\mathrm{S}}-T_{\mathrm{r}}
$$

where $p_{\mathrm{A}}, p_{\mathrm{B}}, p_{\mathrm{C}}$ and $p_{\mathrm{D}}$ are the pressures of combustion chamber A (driving pressure), combustion chamber B (load pressure), scavenge chamber $\mathrm{C}$ (load pressure), and scavenge chamber D (load pressure), respectively; $A_{\mathrm{R}}$ and $L_{\mathrm{R}}$ are the arm area of the center swing and the distance between equivalent driving force acting points on the center swing and the center axis (i.e. center swing axis) at the side of the combustion chambers, respectively; $A_{\mathrm{S}}$ and $L_{\mathrm{S}}$ are the arm area of the center swing and the distance between equivalent driving force acting points on the center swing and the center swing axis at the side of scavenge chambers, respectively; $I$ is the moment of inertia of the center swing assembly, and the external load will also be included in this term.

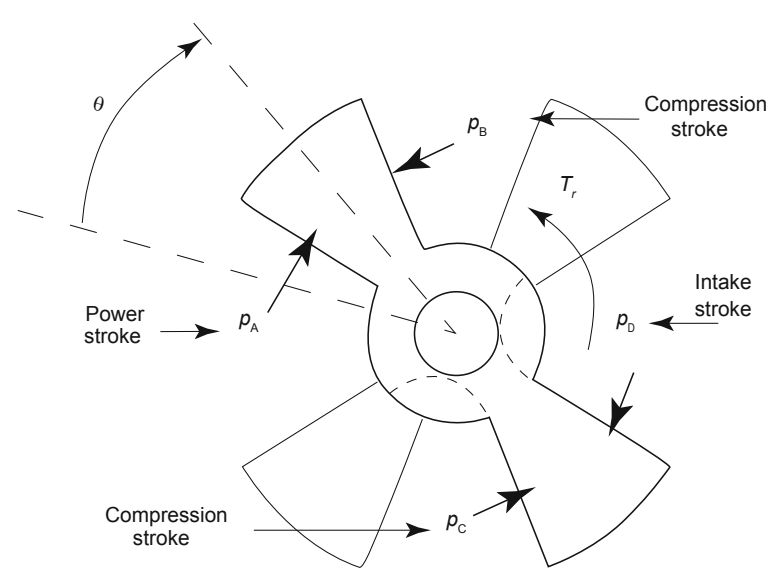

Fig. 2 Systematic dynamic model

In Eq. (1), $T_{\mathrm{r}}$ is the external torque acting on center swing,

$$
T_{\mathrm{r}}=T_{\mathrm{e}}+T_{f}
$$

where $T_{\mathrm{e}}$ is the electromagnetic resistant torque when generating electric power; $T_{\mathrm{f}}$ is the friction resistant torque. According to the electric power generating theory, the generated voltages can be expressed as:

$$
e(t)=B L r_{\mathrm{g}} \dot{\theta}
$$

where $B$ is the magnetic field intensity; $L$ is the electric coil length; $r_{\mathrm{g}}$ is the rotor radius of electric generator; $\dot{\theta}$ is the angular velocity of rotor (or center swing). If the load of electric generator is $R_{1}$ (shown in Fig. 3), the induced current can be expressed as:

$$
i(t)=\frac{e(t)}{R_{1}}
$$

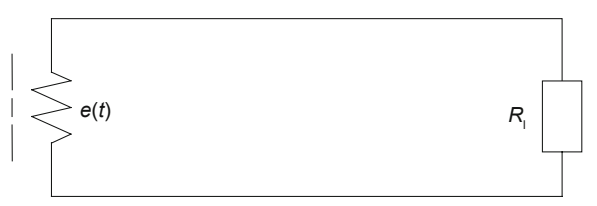

Fig. 3 Schematic diagram of power generation
According to the electric power generation theory, the relationship between electromagnetic resistant torque and induced current $i(t)$ can be expressed as:

$$
T_{\mathrm{e}}=B L r_{\mathrm{g}} i(t)
$$

Substituting Eqs. (3), (4) and (5) into Eq. (2) gives:

$$
T_{\mathrm{r}}=\frac{B^{2} L^{2} r_{\mathrm{g}}^{2} \dot{\theta}}{R_{\mathrm{l}}}+T_{f}
$$

For an electric power generator with fixed load $R_{1}$, $B^{2} L^{2} r^{2} / R_{1}$ will be a constant coefficient. Assuming that the friction torque $T_{\mathrm{f}}$ is also a constant, then the dynamic model of MFPSE will become:

$$
I \ddot{\theta}=\left(p_{\mathrm{A}}-p_{\mathrm{B}}\right) A_{\mathrm{R}} L_{\mathrm{R}}-\left(p_{\mathrm{C}}-p_{\mathrm{D}}\right) A_{S} L_{\mathrm{S}}-\frac{B^{2} L^{2} r_{\mathrm{g}}^{2} \dot{\theta}}{R_{\mathrm{l}}}-T_{f}
$$

In Eq. (7), if all chambers' pressures are determined for any instant of time. The swing angle of MFPSE can be found for a given generator.

\section{Thermodynamic models of MFPSE}

Based on the first law of thermodynamics for an open system, we assume that: (1) the working fluid is a mixture of ideal gases; (2) the pressure is uniform throughout the control volume; (3) the temperature is uniform within both burned and unburned gases; (4) there is no heat transfer between the burned and unburned gases; and (5) the burned gases are in the chemical equilibrium, and unburned gases are unchanged.

Then, the temperature derivative $\dot{T}$ with time $t$ in the control volume can be derived (Heywood, 1988):

$$
\begin{aligned}
\dot{T}= & \frac{R T}{C_{v}}\left[\dot{x}_{\mathrm{b}}\left(\frac{R_{\mathrm{b}}-R_{\mathrm{u}}}{R}+\frac{h_{\mathrm{u}}-h_{\mathrm{b}}}{R T}\right)+\frac{\dot{m}}{m}-\frac{\dot{V}}{V}\right]+ \\
& \frac{1}{m C_{v}}\left[\sum_{i} \dot{m} h-\dot{Q}_{\mathrm{W}}\right]
\end{aligned}
$$

The pressure derivative $\dot{p}_{\text {with }}$ time $t$ in the control volume can be expressed as:

$$
\dot{p}=p\left[\dot{x}_{\mathrm{b}} \frac{R_{\mathrm{b}}-R_{\mathrm{u}}}{R}+\frac{\dot{T}}{T}+\frac{\dot{m}}{m}-\frac{\dot{V}}{V}\right]
$$

where subscripts $\mathrm{b}$ and $\mathrm{u}$ denote the burned gas and unburned gas, respectively; subscript $i$ denotes the species in the gas mixture, i.e. $\mathrm{H}_{2} \mathrm{O}, \mathrm{CO}_{2}, \mathrm{O}_{2}, \mathrm{~N}_{2}$, and fuel.

Once all terms on the right-hand side of Eqs. (8) and (9) are known, the temperatures and pressures of the working fluid inside each chamber can be determined for any instant of time $t$ by recursively applying these equations to each individual process of MFPSE.

The main purpose of this article is to estimate the performance characteristics and validate the MFPSE's feasibility; as a result, the leakage between adjacent chambers is neglected.

\subsection{Thermodynamic model for intake process}

The intake process occurs in two scavenge chambers. In 
the control volume, only intake port is opened, the burned mass fraction $\dot{x}_{\mathrm{b}}$ is expressed as:

$$
\dot{x}_{\mathrm{b}}=\frac{\dot{m}_{i}}{m}\left(x_{\mathrm{b} i}-x_{\mathrm{b}}\right)
$$

The total mass flow rate $\dot{m}$ is expresses for the intake process as:

$$
\dot{m}=\dot{m}_{i}
$$

\subsection{Thermodynamic model for compression process}

After the exhaust port is closed by the center swing, the control volume in the combustion chamber starts to be compressed. In addition, the compression process also happened in both the scavenge chambers. The mass fraction burned $\dot{x}_{\mathrm{b}}$ identically equals zero, and the total mass flow rate of the system also equals zero.

\subsection{Thermodynamic model for combustion process}

In order to simplify the calculation model, we assume that the burned fraction for the combustion process is a known input model, and it is provided by the Wiebe function (Ramos, 1989).

$$
x_{\mathrm{b}}=1-x_{\mathrm{u} 0} \exp \left[-a\left(\frac{t}{\tau_{\mathrm{b}}}\right)^{m+1}\right]
$$

where $\tau_{\mathrm{b}}$ is the burn duration; $x_{\mathrm{u} 0}$ is the initial fresh charge fraction prior to combustion; $a$ and $m$ are variable parameters, and determined by a set of typical values.

The mass burning rate can be obtained from the derivative of the Wiebe function with respect to time $t$,

$$
\dot{x}_{\mathrm{bW}}=a(m+1) x_{\mathrm{u} 0} \frac{t^{m}}{\tau_{\mathrm{b}}^{m+1}} \exp \left[-a\left(\frac{t}{\tau_{\mathrm{b}}}\right)^{m+1}\right]
$$

\subsection{Thermodynamic model for scavenge process}

For a 2-stroke cycle internal combustion engine, its thermodynamic model is very complex in the scavenge process. The scavenge process of MFPSE includes three subprocesses, i.e. free exhaust process, scavenge process, and post exhaust process.

\subsubsection{Free exhaust process}

This process occurs in two combustion chambers, we assume that the fuel is burned out in the combustion process, and then the burned mass fraction is not changed in the free exhaust process.

$$
\dot{x}_{\mathrm{b}}=1
$$

The total mass flow rate of the system for the control volume in the free exhaust process can be expressed as:

$$
\dot{m}=\dot{m}_{\mathrm{e}}
$$

In this process, the direction of the mass flow rate is determined by the pressures in the controlled volume and the pressure outside the exhaust port.

\subsubsection{Scavenge process}

In this process, combustion chamber $\mathrm{A}$ is an open thermodynamic system. There are two types of mass exchanges in the control volume: (1) the fresh charge in scavenge chamber $\mathrm{A}$ is forced to flow into combustion chamber A through scavenge port A by pressure, and (2) the combined gas (fresh charge and burned gas) is forced to flow into manifold through exhaust port. Thus, the burned mass fraction can be expressed as follows:

$$
\dot{x}_{\mathrm{b}}=\frac{\dot{m}_{i}}{m}\left(x_{\mathrm{b} i}-x_{\mathrm{b}}\right)+\frac{\dot{m}_{\mathrm{e}}}{m}\left(x_{\mathrm{be}}-x_{\mathrm{b}}\right)
$$

The mass flow rate in the control volume is

$$
\dot{m}=\dot{m}_{i}+\dot{m}_{\mathrm{e}}
$$

where $\dot{m}_{i}$ is the mass flow rate from the scavenge chamber A to the control volume; $\dot{m}_{\mathrm{e}}$ is the mass flow rate from the control volume to the exhaust port.

\subsubsection{Post exhaust process}

The post exhaust process could not be avoided in the working process of an internal combustion engine. In this process, the replaced gas obtained from scavenge process overflows from the combustion the chamber A to the exhaust port, as a result, part of fresh charge is lost. The burned mass fraction can be expressed as:

$$
\dot{x}_{\mathrm{b}}=\frac{\dot{m}_{\mathrm{e}}}{m}\left(x_{\mathrm{be}}-x_{\mathrm{b}}\right)
$$

The total mass flow rate of the system is

$$
\dot{m}=\dot{m}_{\mathrm{e}}
$$

In a whole cycle, once the mass burning rate is determined, by applying those equations to each working process, the temperature and pressure at any time can be calculated. At the same time, the swing angle and swing angular velocity of the center swing can also be calculated from Eq. (7).

\section{Performance simulation of MFPSE}

\subsection{Geometric parameters and initial conditions}

The geometric parameters of MFPSE are defined in Fig. 4, where $\theta_{\mathrm{B}}$ is $120^{\circ}$, the included angle of center swing $\theta_{\mathrm{S}}$ is $44^{\circ}$, the exhaust beginning angle $\theta_{\mathrm{EB}}$ is $39.5^{\circ}$, and the scavenge beginning angle $\theta_{\mathrm{SB}}$ is $43.5^{\circ}$.

The outer diameter of all chambers $d_{\mathrm{B}}$ is $46 \mathrm{~mm}$, the inner diameter of center swing $d_{\mathrm{H}}$ is $25 \mathrm{~mm}$, the shaft diameter of center swing $d_{\mathrm{HH}}$ is $8 \mathrm{~mm}$, the thickness of the body is $18 \mathrm{~mm}$, the width of exhaust port $B_{\mathrm{E}}$ is $12 \mathrm{~mm}$, the width of scavenge port is $8 \mathrm{~mm}$, the spare volume of spark tap is $199 \mathrm{~mm}^{3}$, and the spare volume of scavenge chamber is $2,651 \mathrm{~mm}^{3}$. 


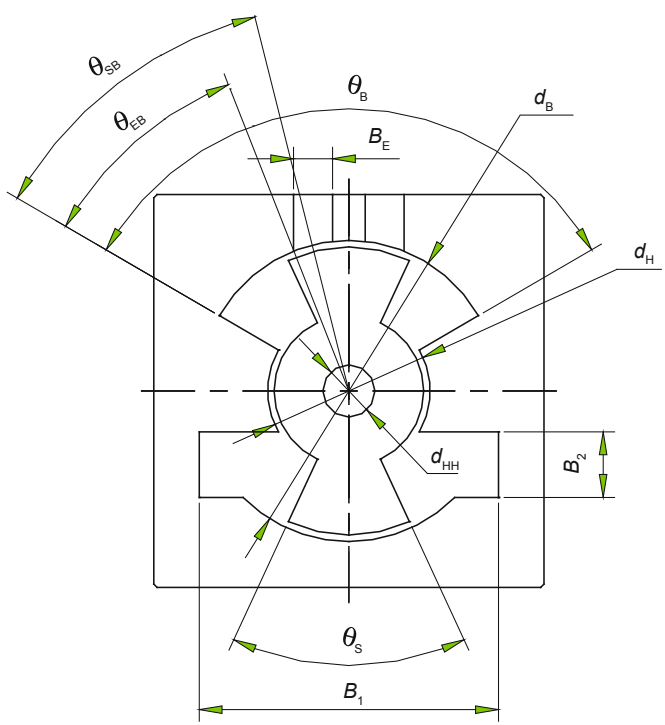

Fig. 4 Geometric parameters of MFPSE

The initial state of each chamber is defined as the state when the angular velocity of center swing is zero. The initial simulation conditions are given in Table 1.

In order to find out the essential properties of MFPSE and to simplify the simulation models, the heat loss and the leakage between adjacent chambers are neglected. At the same time, In order to avoid overestimating the performance of MFPSE and to decrease the negative influence due to simplification, the initial parameters are given conservatively, for example, the port exhaust coefficient is 0.7 , less than its typical value of 0.75 to 0.80 .

Table 1 Initial parameters of MFPSE

\begin{tabular}{cc}
\hline Initial parameters & Value \\
\hline Equivalent fuel/air ratio & 1.0 \\
Reactants & $\mathrm{C}_{8} \mathrm{H}_{18}$ and air \\
Intake pressure, MPa & 0.1 \\
Intake temperature, $\mathrm{K}$ & 300 \\
Exhaust manifold pressure, $\mathrm{MPa}$ & 0.1 \\
Exhaust manifold temperature, $\mathrm{K}$ & 300 \\
Reed valve close time, $\mathrm{s}$ & 0.001 \\
Combustion duration, $\mathrm{s}$ & 0.0038 \\
Parameters of the Wiebe function & $a=5, m=1.05$ \\
\hline
\end{tabular}

\subsection{Convergence criteria of integration}

MFPSE belongs to the scope of free-piston of internal combustion engines, and its compression ratio is variable. The integration process is terminated while the calculation results satisfy all of the four convergence criteria, (1) the difference between the initial parameters in combustion chamber $\mathrm{A}$ and the final parameters in combustion camber B is smaller than a set of given control values; (2) the difference between the initial parameters in scavenge chamber $\mathrm{A}$ and the final parameters in scavenge camber B is smaller than a set of given control values; (3) the difference between the initial spare angle and the calculated spare angle is smaller then a control value; and (4) the difference between the initial mass burned fraction in combustion chamber A and the final mass burned fraction is smaller than a given control value.

In the integration process, the program will re-executed after adjusting the initial parameters if any convergence criterion is not satisfied till all convergence criterions are satisfied.

\subsection{Simulation results and performance analysis}

In the working process of MFPSE, the resistant torque $T_{\mathrm{r}}$ is proportional to the angular velocity of center swing. For a given electric power generator, if the external load $R_{1}$ is not changed, the coefficient of angular velocity in Eq. (7) will become a constant $K$ (named electric load coefficient),

$$
K=\frac{B^{2} L^{2} r_{\mathrm{R}}^{2}}{R_{1}}
$$

The rotor inertia of the electric power generator is larger than the inertia of the center swing and output shaft assembly, $N$ is introduced as the mass load coefficient and expressed as:

$$
N=\frac{I_{\text {rotor }}+I_{\text {swing }}}{I_{\text {swing }}}
$$

If the throttle of the carburetor is fully-opened, $K=0.006$, and $N=5$, the simulation results are listed in Table 2, the swing angle and angular velocity of the center swing in one cycle is shown in Fig. 5, the pressure of the combustion chamber

\begin{tabular}{|c|c|}
\hline Performance & Value \\
\hline Swing frequency, $\mathrm{Hz}$ & 37.3 \\
\hline Indicated work in a cycle, $\mathrm{J}$ & 0.8155 \\
\hline Pumping loss in a cycle, $\mathrm{J}$ & 0.1428 \\
\hline Net work in a cycle, $\mathrm{J}$ & 0.6727 \\
\hline Indicated power, $\mathrm{W}$ & 60.85 \\
\hline Net power, W & 50.2 \\
\hline Average indicated pressure, $\mathrm{MPa}$ & 0.214 \\
\hline Specific fuel consumption, $\mathrm{g} /(\mathrm{kW} \cdot \mathrm{h})$ & 507.56 \\
\hline Fuel efficiency, \% & 16.31 \\
\hline Compression ratio in combustion chamber & 7.23 \\
\hline Compression ratio in scavenge chamber & 1.17 \\
\hline Spare angle, degree & 5.40 \\
\hline Displacement, $\mathrm{mm}^{3}$ & 3818.7 \\
\hline Burned fraction after scavenge & 0.234 \\
\hline
\end{tabular}

Table 2 Simulation results 
and its scavenge chamber in one cycle is shown in Fig. 6, $p$ - $V$ diagram is shown in Fig. 7, in which the solid line denotes the pressure in the combustion chamber, and the dotted line denotes the pressure in the scavenge chamber.

By increasing $K$ from 0.004 to 0.006 while $N=5$, the swing frequency of center swing decreases from 42.64 to $37.31 \mathrm{~Hz}$, the indicated work increases from 0.7277 to $0.8155 \mathrm{~J}$, the indicated power decreases from 62.05 to $60.85 \mathrm{~W}$ while the net power increases from 49.74 to $50.19 \mathrm{~W}$. The reason is that the increased indicated work is neutralized by the increased time of each cycle. At the mean time, the swing angular velocity decreases from 150.751 to $127.59 \mathrm{rad} / \mathrm{s}$ because the electric load is inversely proportional to the angular velocity.
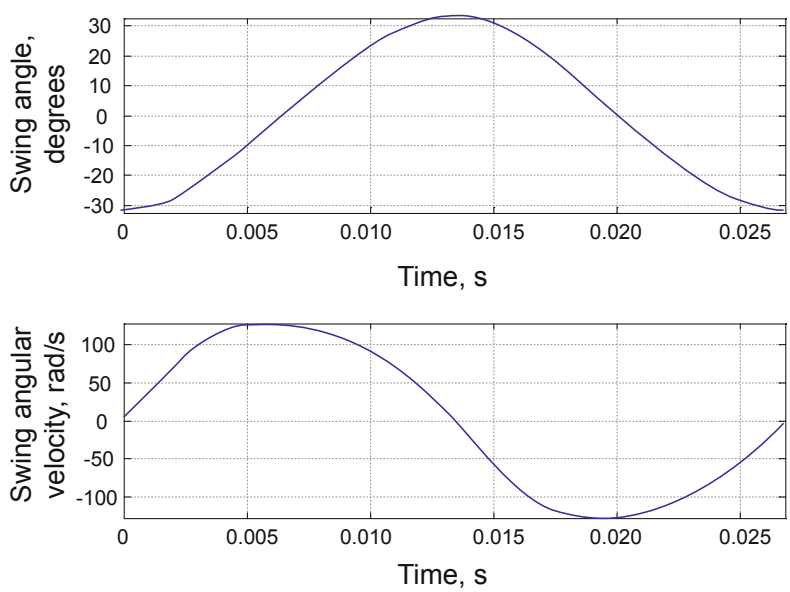

Fig. 5 Swing angle and angular velocity of the center swing in a cycle

In above two cases, the specific fuel consumption and fuel efficiency are $558.96 \mathrm{~g} /(\mathrm{kW} \cdot \mathrm{h}), 14.81 \%$ and $507.56 \mathrm{~g} /(\mathrm{kW} \cdot \mathrm{h})$, $16.31 \%$, respectively. The specific fuel consumption of the former increases by $10 \%$, while the fuel efficiency decreases by $10 \%$. In the view of whole engine, the fuel consumption of the former is $34.7 \mathrm{~g} / \mathrm{h}$, and that of the latter is $30.4 \mathrm{~g} / \mathrm{h}$.

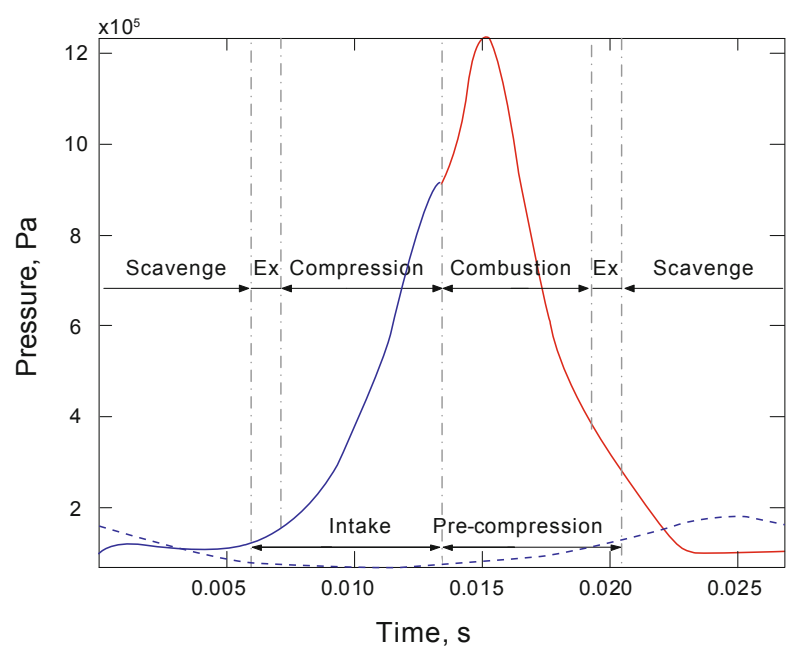

Fig. 6 Pressures of combustion chamber and its corresponding scavenge chamber in one cycle

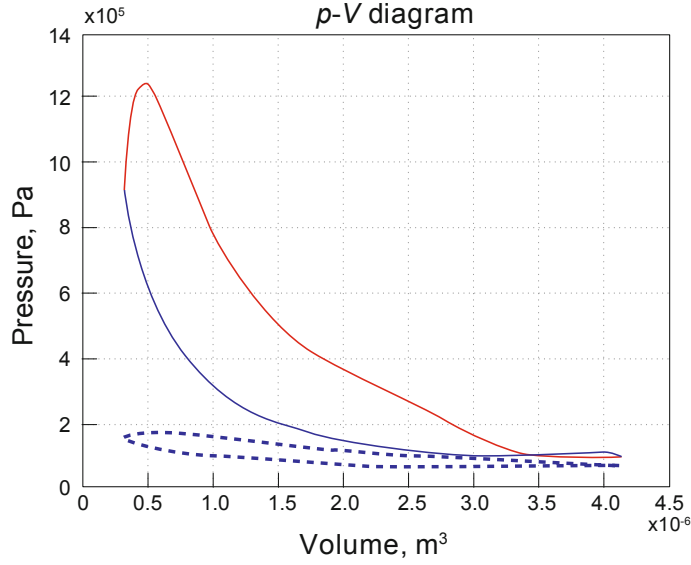

Fig. $7 p$ - $V$ diagram of combustion chamber and its corresponding scavenge chamber

\section{Conclusions}

Based on the open thermodynamic system, MFPSE's performance is evaluated by means of simulation. This method is especially suitable for the free-piston internal combustion engine.

The conclusion can be drawn as follows:

1) If mass load is not changed, the swing frequency, swing angle, and swing angular velocity of the center swing decrease when the electric load increases. However, the output power will change slight if the electric load changes in a specific range, in this process MFPSE adjusts its working state automatically.

2) MFPSE's performance will become worse if the electric load is too low. The reason is that the duration of gas exchange process is very short.

3) The simulation results indicate that MFPSE is feasible in the view of working principle although some unimportant factors are neglected.

\section{References}

Epstein A H, Senturia S D, Al-Midani O, et al. Micro-heat engines, gas turbines, and rocket engines: the MIT microengine project. The 28th AIAA Fluid Dynamics Conference held in Snowmass Village, Columbia. 1997a (Paper No. AIAA-1997-1773)

Epstein A H, Senturia S D, Anathasuresh G, et al. Power MEMS and micro engines. Proceedings of the IEEE Transducers ' 97 Conference held in Chicago, Illinois. 1997b. 2: 753-756

Epstein A H. Millimeter-scale MEMS gas turbine engines. Proceedings of ASME Turbo Expo 2003 held in Atlanta. 2003. 1: 1-28

Fernandez-Pello A C. Micro-power generation using combustion: issues and approaches. Proceedings of the 29th International Symposium on Combustion held in Sapporo, Japan. 2002. 29: 883-899

Fu K, Knobloch A J, Cooley B A, et al. Microscale combustion research for applications to MEMS rotary IC engine. Proceedings of the National Heat Transfer Conference. 2001a. 1: 613-618

Fu K, Knobloch A J, Martinez F C, et al. Design and experimental results of small-scale rotary engines. Proceedings of 2001 ASME International Mechanical Engineering Congress and Exposition held in New York, NY. 2001b. 41: 295-302

$\mathrm{Fu} \mathrm{K}$, Knobloch A J, Martinez F C, et al. Design and fabrication of a silicon-based MEMS rotary engine. Proceedings of 2001 ASME International Mechanical Engineering Congress and Exposition held 
in New York, NY. 2001c. 41: 303-308

Heywood J B. Internal Combustion Fundamentals. New York: McGrawHill Book Company. 1988. 100-154

Isomura $\mathrm{K}$ and Tanaka $\mathrm{S}$. Component development of micromachined gas turbine generators. Proceedings of 2nd International Conference on Power MEMS 2002 held in Tsukuba, Japan. 2002. 32-35

Isomura K, Tanaka S, Togo S, et al. Development of high speed microgas bearing for 3-dimensional micro-turbine machines. Proceedings of 4th International Conference on Power MEMS held in Kyoto, Japan. 2004. 76-79

Kudijiang M. Design, analysis, and experimentation of a micro internal combustion swing engine. Ph.D Thesis. University of Michigan, Ann Arbor. 2000

Mehra A. Development of a High Power Density Combustion System for a Silicon Micro Gas Turbine Engine. Ph.D Thesis. MIT, Cambridge. 2000
Ramos J I. International Combustion Engine Modeling. New York: Hemisphere Publishing Corporation. 1989. 14-85

Shan X C, Wang Z F, Jin Y F, et al. A micro power generation system with gas turbine engine and piezo converter. Proceedings of 4th International Conference on Power MEMS held in Kyoto, Japan. 2004. 162-166

Waitz I A, Gauba G and Tzeng Y S. Combustors for micro-gas turbine engines. Journal of Fluids Engineering, ASME. 1998. 120: 109-117

Werner J A, Dahm N J, Kevin M, et al. Micro internal combustion swing engine (MICSE) for portable power generation systems. The 40th AIAA Aerospace Sciences Meeting held in Reno, Nevada. 2002 (Paper No. 2002-0722)

Zhang S M, Wang J S and Guo Z P. Novel micro free-piston swing engine (MFPSE) and its feasibility validation. Tsinghua Science and Technology. 2005. 10(3): 381-386

(Edited by Sun Yanhua) 